\title{
ISTRAŽIVANJE LOJALNOSTI ZAPOSLENIH U ODNOSU NA SOCIO-DEMOGRAFSKE KARAKTERISTIKE ZAPOSLENIH
}

\section{RESEARCH OF EMPLOYEES LOYALTY IN RELATION TO SOCIO-DEMOGRAPHIC CHARACTERISTICS OF EMPLOYEES}

\author{
Dubravka Klisara, Fakultet tehničkih nauka, Novi Sad
}

\section{Oblast - INDUSTRIJSKO INŽENJERSTVO I INŽENJERSKI MENADŽMENT}

Kratak sadržaj: Cilj rada jeste ustanoviti uticaje sociodemografskih osobina zaposlenih na lojalnost. Da li postoji razlika u zastupljenosti ove osobine kod zaposlenih koji imaju niži stepen stručne spreme i kod onih koji imaju viši stepen? Postavlja se pitanje da li je lojalnost zaposlenih na nižim pozicijama na drugačijem nivou od onih koji su na višim? Istraživanje je rađeno u martu 2019. godine $i$ u njemu je učestvovalo 80 ispitanika od kojih polovina ima viši stepen stručne spreme $i$ radi na višim pozicijama u firmi, dok druga polovina ima nižu stručnu spremu $i$ radi na nižim pozicijama. Dobijene informacije su obrađene u statističkom programu SPSS. Rezultati ukazuju na to da postoji veza između stepena stručne spreme, pozicije $i$ odnosa zaposlenih $i$ menadźmenta na lojalnost.

Ključne reči: Lojalnost, socio-demografske osobine, stepen obrazovanja, pozicija, SPSS.

Abstract: The aim of the paper is to determine if socio-
demographic characteristics of employees have an impact
on loyalty. Is there a difference among employees, based
on their education level, when it comes to loyalty
expression? The next question would be: whether the
employees at the lower work positions show different
level of loyalty than those who are engaged in senior
business positions? The research was conducted in March
2019 with 80 participants taking part in it. Half of these
participants have a high degree of professional skills and
work in senior positions while the other half has a lower
professional qualification and work in lower work
positions. The obtained information are processed using
the SPSS program. The results indicate there is coherence
between the education degree level, and the work position
on the one hand, and the attitude of employees when it
comes to loyalty, on the other.

Keywords: Loyalty, socio-demographic characteristics, education level, work positions, SPSS.

\section{NAPOMENA:}

Ovaj rad proistekao je iz master rada čiji mentor je bila dr Ivana Katić vanredni prof.

\section{UVOD}

Znanja i veštine čoveka jesu ti koji pokreću ceo proces proizvodnje zato se radnik odnosno zaposleni sve češće stavlja u sam centar važnosti za jednu organizaciju. Takođe, savremena tehnologija predstavlja jedan od osnovnih faktora uspešne organizacije. Poznavanje ovakve vrste tehnologije, ujedno i njeno posedovanje, veoma je važno u borbi protiv sve oštrije konkurencije na tržištu. Ipak, to je samo jedan od uslova da se postigne uspeh na tržištu. Ono što je ključno u ovoj sve oštrijoj i otvorenijoj borbi jeste način na koji zaposleni doživljavaju svoj posao i naravno organizaciju u kojoj rade $i$ sopstvenu lojalnost prema njoj. Njihov nivo zadovoljstva i motivacije će direktno uticati na kvalitet posla koji obavljaju zbog čega je važno stvoriti takvu radnu klimu koja će u ovom smislu pozitivno uticati na zaposlene. Presudnu ulogu u ovome često ima menadžment. Visok stepen lojalnosti zaposlenih je najviši stepen pozitivnih međuljudskih odnosa koje menadžment može postići u kompaniji. U svakom preduzeću važan je razvoj karijere, a značajne posledice na razvoj karijere imaju sledeće karakteristike: pol, radno iskustvo, materijalno stanje i savesnost (Katić I, Ivanišević A, Grubić-Nešić L, Penezić N. 2017).

\section{LOJALNOST}

Lojalnost zaposlenih možemo definisati kao psihološku povezanost ili posvećenost organizaciji. Postoji više parametara lojalnosti koji utiču na pojedinca na način da on oseti potrebu da bude veran organizaciji u kojoj radi. Finansijsko planiranje zaposlenima pruža osećaj sigurnosti kao osnovni motiv Maslovljeve teorije potreba (Ivanišević A, Katić I, Marjan L, Buchmeister B 2016). Kako preduzeća sve više uključuju informacije od svojih klijenata $\mathrm{u}$ procese kreiranja proizvoda ili usluga, neophodno je da zaposleni budu aktivno uključeni $u$ proces odlučivanja (Leber M, Ivanišević A, Borocki J, Radišić M, Slusarczyk B. 2018). Potrebno je u svakoj organizaciji unaprediti menadžerske mogućnosti kroz motivisanje i razvijanje zaposlenih kao kompetitivne prednosti (Cvijić M, Tatarski J, Katić I, Vekić A, Borocki J. 2019).

Sukob lojalnosti je izraz koji označava problem koji nastaje kada se lojalnost od druge strane traži po potrebi. Najbolji primer za to je onaj gde radnik ne deli iste ciljeve i vrednosti sa kompanijom, a od njega se zahteva da joj bude lojalan. Lojalnost zaposlenih zavisi od međuljudski 
odnosa koji ukoliko se percipiraju pozitivno u smislu kvalitetnog tinskog rada, mogu značajno uticati na viši stepen lojalnosti kod zaposlenih (Zubanov V, Katić I, Grubić-Nešić L, Berber N. 2017).

Merenje lojalnosti nije uvek jednostavno, ali postoje znaci koji jasno ukazuju na ovo. Lojalnost se izražava u mislima $i$ akcijama $i$ to je psihološka vezanost $i$ posvećenost organizaciji.

\section{POSVEĆENOST ORGANIZACIJI}

Organizaciona posvećenost (engleski Organizational Commitment) predstavlja pozitivne stavove koje zaposleni oseća prema organizaciji u kojoj radi. Ona donosi dodatno zadovoljstvo zaposlenom što utiče na njegovu lojalnost kompaniji. Posvećeni članovi su odani svojoj kompaniji i spremni da se žrtvuju za nju. Posvećenost podrazumeva veliku zainteresovanost zaposlenih za posao koji treba da obave i visok nivo motivacije. Postoje mnogi pozitivni efekti organizacione posvećenosti, a neki od njih su ređe i kraće odsustvo sa posla, veća motivisanost, veći stepen produktivnosti, manja fluktuacija. Najčešće navođena definicija je Schein-ova, prema kojoj je organizacija ,racionalno koordinisanje aktivnosti niza ljudi u svrhu postizanja nekih zajedničkih ciljeva, a uz pomoć podjele rada i funkcija, i preko hijerarhije autoriteta i odgovornosti" (Pec, 1987). Osim benefita za organizaciju, pozitivni efekti posvećenosti su primetni i na ličnom nivou pojedinca. Oni se ogledaju u povećanju zadovoljstva poslom što se neretko prenosi i na privatni život.

\section{POJAM VREDNOSTI}

Ukoliko posmatramo sam izraz "vrednosti", ovaj termin se odnosi na objekat ili pojave kojima se pripisuje status vrednosti. Ona označava najopštije verovanje o tome šta je i koliko valjano i korisno, odnosno šta je nedopustivo i nepoželjno. Vrednost se vezuje za individuu i ima subjektivni karakter. S obzirom da je zastupljen u raznim disciplinama, postoji više definicija ovog pojma.

Mnogi najkompletnijom smatraju Pantićevu definiciju iz razloga što su u njoj sadržane sve bitne karakteristike pojma:

"Vrednosti su relativno stabilne, opšte i hijerarhijski organizovane karakteristike pojedinaca (dispozicije) i grupa (elementi društvene svesti), formirane međusobnim delovanjem istorijskih, aktuelno-socijalnih i individualnih činilaca, koje zbog tako pripisane poželjnosti usmeravaju ponašanje svojih nosilaca ka određenim ciljevima“ (Pantić, 1990).

U razumevanju teme vezane za zadovoljstvo poslom, od pomoći može biti teorija vrednosti Edvina Loka. Prema ovoj teoriji, zaposleni su zadovoljni poslom u onoj meri u kojoj su zadovoljni ishodima samog posla.

\section{ZADOVOLJSTVO ZAPOSLENIH}

Mnoge studije su pokazale da je zadovoljstvo radnika jaka determinanta organizacijske posvećenosti i lojalnosti (Mak \& Sockel 2001; Martensen \& Gronholdt, 2001). Zadovoljstvo poslom se može definisati kao stav prema poslu, pri čemu je stav emocionalna reakcija prema nečem i može varirati od izuzetno pozitivnog do izuzetno negativnog. Zadovoljstvo poslom se takođe može se definisati kao kognitivna (pretpostavke i verovanja na poslu), afektivna (osećanja prema poslu) i evaluativna (ocena posla) reakcija pojedinca na svoj posao. Jedna od najpoznatijih teorija zadovoljstva poslom je Hercbergova teorija dva faktora, pri čemu ovaj američki psiholog (Frederick Herzberg) u fokus svoje teorije motivacije stavlja zadovoljstvo i nezadovoljstvo poslom. Hercberg razlikuje: (1) Higijenske faktore, (2) Motivatore. Higijenski faktori - još se nazivaju i ekstrinzičnim i predstavljaju radni kontekst, na primer, uslove rada, politiku preduzeća, stil rukovođenja i dr.

Motivatori - nazivaju se i intrinzični faktori i predstavljaju potrebe višeg nivoa koje utiču na zadovoljstvo kada su ispunjene, ali ne utiču na nezadovoljstvo kada nisu.

\section{MOTIVACIJA ZAPOSLENIH}

Važna odgovornost strategijskog menadžmenta je izgradnja i održavanje ljudskih resursa tako da se interesi ljudi u organizaciji optimiziraju sa interesima organizacije. Sve ovo jasno obuhvata liderstvo i podesnu harizmu izvesnog broja menadžera (Mašić, 2009). Motivacija se može definisati kao proces svesnog pokretanja i usmeravanja aktivnosti ka ostvarenju određenog cilja. Motivacija za rad je kompleks sila koje iniciraju i zadržavaju zaposlenog da radi u određenoj organizaciji (Bahtijarević \& Šiber, 1999).

Menadžment mora razumeti ljude generalno, njihovo ponašanje, mora ostvariti komunikaciju, mora ih motivisati kako bi što bolje ostvarili zacrtane planove samog preduzeća.

Motivatori podstiču pojedinca na delovanje. Delovanje motivatora povećava potrebe koje postoje i bez njih. Može se primetiti mnoštvo motivatora koji deluju $u$ čovekovoj sredini, a dele se na pozitivne i negativne. Pozitivni omogućavaju opstanak čoveka i to su vazduh, voda i hrana dok negativni ometaju čovekovu aktivnost. Zaposleni koji su motivisani za rad, energičnije ostvaruju ciljeve i razvijaju lojalan odnos prema organizaciji. Ipak, postizanje optimalnog nivoa motivisanosti zaposlenih nije uvek lako. Da bi se neko motivisao moraju se razumeti njegove potrebe i ciljevi.

\section{ISTRAŽIVANJE}

\subsection{Predmet istraživanja}

Predmet istraživanja ovog rada je ispitivanje lojalnosti koju zaposleni osećaju prema kompaniji u kojoj rade.

\subsection{Problem istraživanja}

Pretpostavlja se da su zaposleni koji imaju viši stepen obrazovanja i rade na višim pozicijama (liderskim, koordinatorskim, menadžerskim) lojalni kompaniji. Detaljno su uključeni u poslovanje i razumeju ciljeve kompanije. Isto tako se može pretpostaviti da su manje obrazovani zaposleni, koji rade na nižim, izvršnim pozicijama, manje lojalni jer se često dešava da nisu dovoljno upućeni u ciljeve kompanije, da ne razumeju čime se ona tačno bavi i zbog čega je njihov posao važan. Problem istraživanja se odnosi na to da li i u kojoj meri 
radna pozicija i stepen obrazovanja utiču na lojalnost zaposlenih prema organizaciji.

\subsection{Cilj istraživanja}

Cilj je otkriti da li postoji razlika između lojalnosti i socio-demografskih karakteristika zaposlenih?

Zadaci su: otkriti da li postoji razlika između lojalnosti zaposlenih sa osnovnim i srednjim obrazovanjem koji su na izvršnim radnim pozicijama $i$ onih sa visokim obrazovanjem koji su zaposleni na koordinatorskim, liderskim i menadžerskim pozicijama?

Takođe je potrebno je istražiti u kolikoj meri su povezani stepen obrazovanja i pozicija na kojoj zaposleni radi sa lojalnošću koju osećaju prema kompaniji?

\subsection{Hipoteze istraživanja}

Za istraživanje određena je opšta hipoteza:

OH1: Postoji povezanost socio-demografskih karakteristika zaposlenih i lojalnosti prema kompaniji

Posebne hipoteze istraživanja su sledeće:

H1: Postoji uticaj stručne spreme zaposlenih na lojalnost kompaniji.

H2: Postoji uticaj nivoa radne pozicije zaposlenih na lojalnost kompaniji.

H3: Postoji uticaj odnosa menadžmenta i zaposlenih na lojalnost zaposlenih.

H4: Zaposleni sa ukupno više staža su lojalniji organizaciji.

H5: Zaposleni sa više staža u kompaniji su lojalniji organizaciji

H6: Postoji uticaj starosti zaposlenih na lojalnost kompaniji.

H7: Postoje međupolne razlike u lojalnosti kompaniji

\subsection{Merni instrumenti}

Za merenje nivoa lojalnosti zaposlenih iz obe grupe (sa nižih i viših pozicija) korišćena su dva upitnika konstruisana za potrebe internih istraživanja zadovoljstva zaposlenih od strane sektora za ljudske resurse kompanije Grundfos d.o.o Srbija 2018. godine. Prvi upitnik se odnosi na socio-demografske karakteristike i sadrži šest pitanja, a drugi ispituje zadovoljstvo zaposlenog samim radom, organizacijom, menadžmentom, kolegama i vrednostima koje se promovišu unutar kompanije u kojoj rade. Ovaj upitnik se sastoji od 17 pitanja.

Ispitanici su imali ponuđenu skalu odgovora (Likertov tip skale): 1- Uopšte se ne slažem sa ovom tvrdnjom, 2Delimično se ne slažem sa ovom tvrdnjom, 3- Nisam siguran/a, 4- Slažem se sa ovom tvrdnjom, 5- U potpunosti se slažem sa ovom tvrdnjom.

\subsection{Uzorak istraživanja}

Istraživanje je obavljeno tokom marta 2019. godine na uzorku od 80 ispitanika od kojih je polovina sa završenom visokom stručnom spremom i radi na koordinatorskim, ekspertskim i menadžerskim pozicijama, a polovina sa završenom srednjom ili osnovnom školom i radi na osnovnim izvršnim pozicijama (radnik u proizvodnji).

\section{Statistička obrada podataka}

Podaci su obrađeni u statističkom programu SPSS, a od metoda su korištene sledeće:
Deskriptivna statistika koja obuhvata frekvencije i procente varijabli, kao i mere centralne tendencije: aritmetičku sredinu i standardnu devijaciju.

Pirsonov koeficijent linearne korelacije je korišten za utvrđivanje povezanosti lojalnosti kompaniji, kao zavisnoj varijabli istraživanja, sa nizom nezavisnih varijabli: stručna sprema, radna pozicija, odnos menadžmenta, dužina staža i starost ispitanika.

T test za nezavisne uzorke je korišten da se utvrdi da li postoji statistički značajna međupolna razlika u lojalnosti kompaniji.

\section{ANALIZA REZULTATA}

Rezultati dobijeni prikazanim istraživanjem ukazuju na sledeće: Što je viša stručna sprema zaposlenih, to oni pokazuju viši nivo lojalnosti kompaniji što potvrđuje koeficijent korelacije koji je statistički značajan na nivou 0,01 . Korelacija je nižeg intenziteta $r=0,36$ i pozitivnog predznaka. Na osnovu ovog rezultata možemo reći da se prva posebna hipoteza prihvata. Druga posebna hipoteza istraživanja glasi: "Postoji uticaj nivoa radne pozicije zaposlenih na lojalnosti kompaniji." Pirsonov koeficijent linearne korelacije je statistički značajan na nivou 0,01 . On iznosi $r=0,41$ što znači da je umerenog intenziteta $i$ pozitivnog predznaka. Ovakav rezultat govori da što je viša radna pozicija zaposlenih, to oni pokazuju viši nivo lojalnosti kompaniji, tako da se druga posebna hipoteza prihvata.

Treća posebna hipoteza istraživanja glasi: "Postoji uticaj odnosa menadžmenta i zaposlenih na lojalnost zaposlenih." Svi dobijeni koeficijenti korelacije su statistički značajni, svi su pozitivnog predznaka i višeg intenziteta i kreću se između 0,68 i 0,78. Na osnovu navedenih rezultata možemo reći da se hipoteza koja govori o uticaju odnosa menadžmenta i zaposlenih na lojalnost zaposlenih prihvata.

Četvrta posebna hipoteza istraživanja glasi: "Zaposleni sa ukupno više staža su lojalniji organizaciji” i proverena je Pirsonovim koeficijentom linearne korelacije između varijabli ukupna dužina staža i skora na upitniku lojalnosti. Dobijeni koeficijent korelacije nije statistički značajan $(\mathrm{r}=0.09)$, tako da hipoteza koja govori o uticaju dužine ukupnog staža zaposlenih na lojalnosti kompaniji, nije prihvaćena.

Peta posebna hipoteza istraživanja glasi: "Zaposleni sa više staža u kompaniji su lojalniji organizaciji” i proverena je Pirsonovim koeficijentom linearne korelacije između varijabli dužina staža u kompaniji u kojoj su zaposleni i ukupnog skora na upitniku lojalnosti. Dobijeni koeficijent korelacije $\mathrm{r}=0,19$ nije statistički značajan, tako da nije prihvaćena hipoteza koja govori da su zaposleni sa više staža u kompaniji lojalniji.

Šesta posebna hipoteza istraživanja glasi: "Postoji uticaj starosti zaposlenih na lojalnost kompaniji. Ova hipoteza je odbačena jer Pirsonov koeficijent korelacije $r=0,17$ nije statistički značajan. Sedma posebna hipoteza istraživanja glasi: "Postoje međupolne razlike u lojalnosti kompaniji". Ispitanici muškog pola u proseku imaju oko 56 bodova $(\mathrm{AS}=55,91)$ na upitniku, dok njihove koleginice imaju u proseku oko 58 bodova $(\mathrm{AS}=57,92)$. T test kojim je proverena ova razlika nije pokazao statističku značajnost. 
S obzirom da su od sedam pojedinačnih hipoteza, tri prihvaćene, a četiri odbačene, opšta hipoteza koja glasi "Postoji povezanost socio-demografskih karakteristika zaposlenih i lojalnosti prema kompaniji" se delimično prihvata.

\section{ZAKLJUČAK}

Ljudski potencijal postao je jedan od ključnih strukturnih elemenata. Vrednost ljudskog kapitala progresivno se povećava počevši od kraja dvadesetog veka. Ova problematika je dostojna pitanja i analize stručne i naučne javnosti budući da je intelektualni kapital inkorporiran $\mathrm{u}$ svim organizacijama izuzimajući važnost faktora veličine (Dmitrović, 2015). Ulaganjem u zaposlene kompanije pokazuju brigu o njima, očekujući zauzvrat da će podstaći veoma bitnu karakteristiku zaposlenih - lojalnost. Jasno je da je lojalnost zaposlenih poželjno ponašanje, ali nju nije uvek lako dostići. Postoje mnoga istraživanja koja se bave ovom temom, ali zbog njene kompleksnosti još uvek nije $\mathrm{u}$ potpunosti istražena te je potrebno uputiti dalja istraživanja u ovom pravcu.

Važno je otkriti koje su to strategije koje povećavaju lojalnost zaposlenih u odnosu na njihove demografske različitosti kako bi se njihovom primenom postigli optimalni rezultati u poslovanju.

\section{LITERATURA}

1. Bahtrijarević, F. (1999) Menadžment ljudskih potencijala, Golden Marketing, Zagreb.

2. Cvijić M., Tatarski J., Katić I., Vekić A, Borocki J.,:Entrepreneurial Orientation of Public Universities in Republic of Serbia-Empirical Study, Sustainability 2019, Special Issue Towards Resilient

Entrepreneurship and Technological Development in Self-Sustainable Economies, 11(6),1509, pp-1-13; https://doi.org/10.3390/su11061509, Received: 26 December 2018 / Revised: 22 February 2019 /

Accepted: 9 March 2019 / Published: 13 March 2019

3. Dmitrović, M. V. (2015). INTELEKTUALNI KAPITAL KAO STRATEŠKA PERFORMANSA ORGANIZACIJE.

4. Ivanišević A., Katić I., Marjan L., Buchmeister B.,: Business plan feedback for cost effective business processes, Advances in Production Engineering \& Management, Vol. 11 (2016) br. 3 ISSN 1854-6250 Print, ISSN 1855-6531 Online, pp. 173-183, http://dx.doi.org/10.14743/apem2016.3.218

5. Katić I., Ivanišević A., Grubić Nešić L., Penezić N.: Effects of Sociodemographic Characteristics and Personality Traits on Career Development, The International Journal of Aging and Human Development, DOI: 10.1177/0091415017743008, 0(0) 1-16, Article first published online: November 24, 2017, ISSN: 0091-4150, Online ISSN: 1541-3535 Volume: 87 issue: 2, page(s): 201-216
6. Leber M., Ivanišević A., Borocki J., Radišić M., Ślusarczyk B. Fostering Alliances with Customers for the Sustainable Product Creation Sustainability 2018, 10(9), 3204, pp. 1-18; https://doi.org/10.3390/su10093204 Received: 25 June 2018 / Revised: 17 August 2018 / Accepted: 28 August 2018 / Published: 7 September 2018

7. Mak, B. and H. Sockel. 2001. A confirmatory factor analysis of IS employee motivation and satisfaction. Information and Management, 38, 265-276.

8. Martensen, A. and L. Gronholdt. 2001. Using employee satisfaction measurement to improve people management: An adaptation of Kano's quality type. Total Quality Management, 12 (7\&8), 949-957.

9. Mašić, B. (2009). Strategijski menadžment, Univerzitet Singidunum, Beograd.

10. Mihica, K. (2015). Parametri koji utječu na lojalnost zaposlenika. Dostupno na: https://repozitorij.unin.hr/islandora/object/unin:763/p review (Posećeno 09.06.2018)

11. Pantić, D. (1990). Promene vrednosnih orijentacija mladih u Srbiji. Beograd. Institut društvenih nauka.

12. Zubanov V., Katić, I., GrubićNešić L, Berber N.: The Role of Management Teams in Business Success: Evidence, Inzinerine Ekonomika_Engineering Economics, 2017, Vol.28 No.1, pp 68-78, DOI: DOI: http://dx.doi.org/10.5755/j01.ee.28.1.15132 Print ISSN: 1392-2785 Online ISSN: 2029-5839

\section{Kratka biografija}

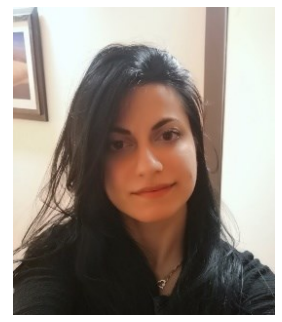

Dubravka Klisara rođena je u Novom Sadu 1989. godine. Diplomske studije završila je na Prirodnomatematičkom fakultetu u Novom Sadu, i stekla zvanje Diplomirani turizmolog. Master studije završila je na Fakultetu tehničkih nauka u Novom Sadu 2019. godine, smer Menadžment ljudskih resursa. 